\title{
MAPPING THE GOALS OF THE BOLOGNA PROCESS
}

\author{
Alexander an Haack, Laura Braun, Ursula Bach, René Vossen, Sabina Jeschke \\ Institute Cluster IMA/ZLW \& IfU of RWTH Aachen University (GERMANY) \\ alexander.anhaack@ima-zlw-ifu.rwth-aachen.de, laura.braun@ima-zlw-ifu.rwth-aachen.de, \\ ursula.bach@ima-zlw-ifu.rwth-aachen.de,rene.vossen@ima-zlw-ifu.rwth-aachen.de, \\ sabina.jeschke@ima-zlw-ifu.rwth-aachen.de
}

\begin{abstract}
The ratification of the Bologna Process in 1999 has led to fundamental changes in the European higher education area. After more than a decade of Bologna reform efforts, the question arises whether and to what degree the declared goals of the Bologna Process (e.g. increasing student mobility and employability) have been achieved in the educational practice, i.e. on the individual university level. This desire points to the question of what these goals exactly are, how they are structured and how to eventually prioritize among them. The search for a comparable systematisation of the reforms objectives unveils only its absence.

This paper presents the work of higher engineering education scientists on the development of a comprehensive understanding of the Bologna Process objectives, their interconnections and practical measures in order to make this large scale reform accessible to the controlling of European universities' decision making. To this aim, the objectives are mapped in the form of a software based system model, according to the theory of System Dynamics. The elements of the model are fully based on the official Bologna declarations, memoranda as well as expert literature. It therefore claims to represent the state of the art on the goals of the Bologna Process. For the first time this system model structures the Bologna goals ordered by levels of hierarchy and it quantifies their dependencies on the basis of the System Dynamics approach. The validity of the model has been assessed based on qualitative and quantitative data, generated in a study involving 29 German experts in the field of higher education specialized on the Bologna Process. Further research will concentrate on a practical application of this system model, including the evaluation of the model's statements. Ultimately, the model's insights will enable European universities to estimate their respective degrees of Bologna goal attainment and to identify key measures for individual improvement.
\end{abstract}

Keywords: Bologna Process goals, system model, higher education reform.

\section{INTRODUCTION}

In the course of the Bologna Process, the European higher education area underwent comprehensive reform whose process of implementation and outcomes have reached both great public and scientific attention. Popular and scientific investigations mainly focus on the appropriateness and the effectiveness of the stipulated Bologna goals and their implementation in the pre-existing higher education systems of the individual member states. As a contrast, the present paper deals with the question of how the Bologna goals are actually interlinked and structured and how their achievement can be measured in several/individual universities. The research was deemed necessary, because of the great effort, universities and national higher education systems have put into the implementation of the reform, without being able to accurately measure their success.

For this purpose an instrument has been developed, based on a complex system model, which effectively maps the various objectives of the Bologna Process including its resulting measures on the institution level. For the first time, this model illustrates and hierarchically structures the entirety of the Bologna goals. By putting the latter into context and by weighing them, universities are able to identify strengths and opportunities in their individual implementation of the Bologna Process. Alongside, the model also systematizes the content of the Bologna declarations by distinguishing genuine objectives from mere measures, which are not desired goals in their own right, but rather agreed upon solutions in order to achieve the chosen objectives. On this basis, European universities can now estimate their individual degree of Bologna goal attainment and hence evaluate both their needs for further optimization and justified content.

The work is part of the effort undertaken by the Competence and Service Center for Teaching and Learning in Engineering Sciences - TeachING-LearnING.EU [1] - to sustainably improve the quality of 
engineering science courses in the context of the Bologna Process. The Competence and Service Center, based at the RWTH Aachen University, the Ruhr-Universität Bochum and the Technische Universität Dortmund, will use the model as a benchmarking tool, in order to identify best practices and expand the insights into effective institutional policies for the engineering sciences education. The piloting application of the Center's insights will be conducted at very large engineering universities in Germany, like the RWTH Aachen University. [2]

This paper presents and discusses the methodological development of the resulting Bologna goal system model, as well as some key findings. In the following an overview of the theoretical background of the Bologna Process is provided as well as of the approach of the presented research.

\subsection{Theoretical background}

Based on their agreement in Sorbonne, in 199929 European countries declared to reorganize their higher education systems as specified by the Bologna declaration [3]. Within this arrangement, ministers of the participating European countries agreed on the concerted pursuit of the goal to use the "European area of higher education as a key way to promote citizens' mobility and employability and the Continent's overall development" [6], as it was laid out by the Sorbonne declaration of 1998 [7]. This general intention resulted on the policy level in the declaration of the following main objectives:

- increasing the compatibility and comparability of European higher education degrees,

- implementation of a two main cycles system (undergraduate and graduate),

- implementation of a system of credits - as in the ECTS,

- the promotion of mobility of students and scientific staff,

- promotion of European co-operation in quality assurance and

- promotion of the necessary European dimensions in higher education. [3]

In the course of the first decade of the new century both the number of countries participating in the Bologna Process as well as the number of objectives pursued increased. At least 46 ministers responsible for higher education in the participating European countries convened in Prague (2001) [6], Berlin (2003) [7], Bergen (2005) [8], London (2007) [9], Leuven (2009) [10], Budapest and Vienna (2010) [11] and Bucharest (2012) [12] to reaffirm their commitment to the determined goals and defined additional objectives for 2020, now under the title of the European Higher Education Area (EHEA) [13, 14]. The promotion of the social dimension [8] and lifelong learning [6] as well as the increase of student participation [6] and international openness [10] are examples for further goals added.

In order to structure the various goals, proclaimed in the Bologna declarations, researchers also try to identify and name superordinate goals. Ceylan et al. (2011) nominates three goals, central to the reform: "promotion of international mobility", "international competitiveness of universities" and "employability of graduates" [15]. As a comparison Witte et al. (2011) frames the top goals to be the "establishment of an attractive, competitive and fair European higher education area with a high mobility of students and scientific staff" [16]. To this day, there is yet no common understanding of one or several superordinate goals for the Bologna Process, not to speak of a comprehensive systematisation. For this reason the present research undertakes the effort to determine and structure these objectives, including the validation of what can be considered the one or several superordinate goals. As no standard method has been able to satisfy the requirements of this research situation, the process of identifying and nominating the super- and subordinate goals for the Bologna goals system model is now described in detail.

\subsection{Description of desk research and its results}

The basis for the system model was a comprehensive study of primary and secondary literature on the Bologna reform. Since no comparable goal centric overview of the Bologna reform had been produced prior to this research, the focus lied especially on the study of the official Bologna reform documents and their discussion in expert literature. In the following the pursued approach and the development of the model is outlined.

The present research effort began with the compilation of all Bologna documents, such as official declarations, memoranda and conference reports. In a first analysis all Bologna objectives have been extracted from the official declarations determined in Bologna [3], Prague [4], Berlin [7], Bergen [8], 
London [9], Leuven [10] and Bucharest [12]. The dependencies between individual goals have been identified based on their definitions.

Within the Bologna declarations, no differentiation has been made between superordinate goals and resulting measures which are to be directly implemented by universities. For example the Bologna goal Establishment of a system of credits - the ECTS [3] approved in the Bologna declaration of 1999 is not merely autotelic, but rather represents a measure to achieve superordinate goals such as Promotion of Mobility [3]. Within the model, all Bologna goals have been structured on the basis of their interdependencies and hence their underlying level of abstraction. A major result of the applied desk research thus is the identification of a set of highest-level objectives.

Three central dimensions of the Bologna Process have been recognized (see also Fig.1): economic efficacy [6], scientific efficacy [6] and social cohesion (the so called "social dimension") [6]. Economic efficacy is mainly influenced by employability of graduates [3] and research findings with commercial relevance [7]. Employability is directly and indirectly rooted in the factors subject-specific competences [17], generic competences (transferable skills) [7], efficiency of academic teaching [17], work experience of graduates [17] and adaptability of graduates [17]. Scientific efficacy is determined by scientific competitiveness of the European higher education area [6], which in the context of the Bologna Process is itself based on the efficiency of university research [6]. Fig.1 is an extract of the software-based mapping of the Bologna goals. It shows the first three levels of the complex system model.

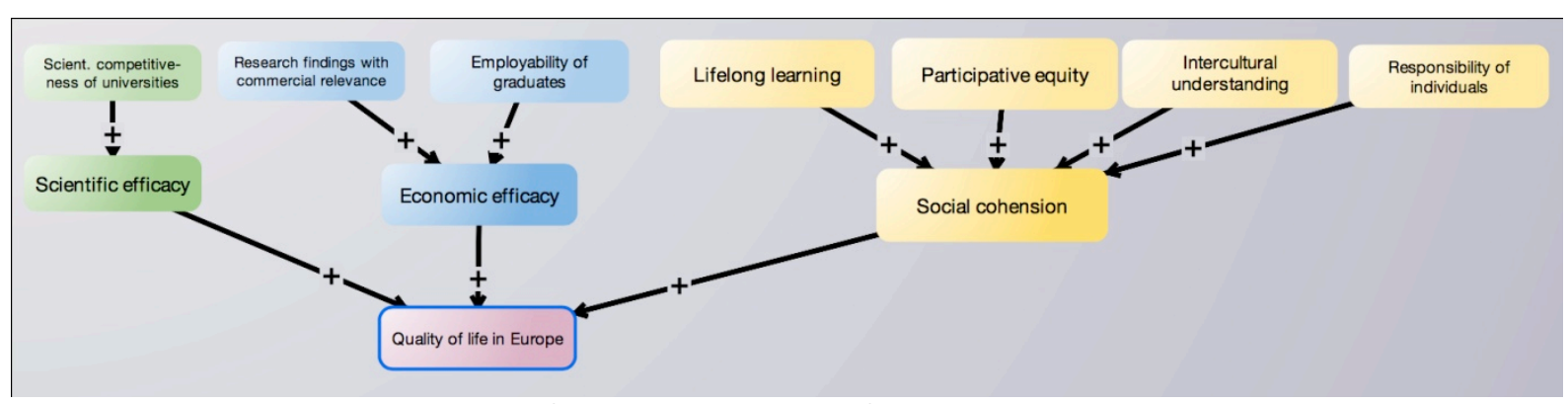

Fig.1: Illustration of the primary levels of the Bologna system model.

In the context of the Bologna Process, participative equity [9], lifelong learning [3], intercultural understanding [8] and responsibility of individuals [17] form the basic components of the dimension social cohesion [6]. As direct and indirect impacts on these variables can be identified e. $\mathrm{g}$. intercultural competences of graduates [8], equal access to academic programmes [7] and ability to participate in higher education [9]. Between the three central dimensions, strong connections are found in the form of abstract factors and practical measures. Central factors, which relate to more than one dimension, are e. g. the efficiency of academic teaching [17], mobility of students and scientific staff [3] and adaptability of graduates [17].

As previously mentioned, no official global objective has been proclaimed for the Bologna Process. Yet, in order to incorporate all objectives in a single model, such a superordinate, unifying objective is needed. The task therefore was to find a term which summarizes the three highest-level goals economic efficacy [6], scientific efficacy [6] and social cohesion [6]. Unarguably the mentioned goals are all part of common national or international political agendas, which leads to the question of the superordinate purpose of such societal action. Studying the field of societal goals development one finds the terms happiness or quality of life, which are defined and used in such a way to frame the global aim of human actions $[18,19]$. In consequence, the item quality of life in Europe was incorporated as the unifying top-level goal within the model.

In the next chapter the theoretical background of the mapping of the Bologna Goals is laid out. Furthermore the software-based illustration of the complex Bologna system model is outlined.

\subsection{Description of the system model}

\subsubsection{Theory of System Dynamics}

The theory of System Dynamics (SD), developed by Jay W. Forrester and advanced by John D. Sterman [20] serves as the basis for the present Bologna system model. "System dynamics is a perspective and set of conceptual tools that enable us to understand the structure and dynamics of complex systems" [20]. According to the method, all relevant factors influencing the considered 
problem scenario and its context as well as their interrelations have to be represented in the system model. The goal is to identify and illustrate the importance of the various factors involved as well as the direct interactions and multi-level cause-and-effect relationships between them. To do so, the technique allows to structurally and quantitatively reproduces the magnitude of effects, the emergence of indirect effects (through feedback loops) as well as the potential delays of certain effects (e. g. through long-term influences). The benefit of the method lies in the functionality to enable the understanding and simulation of complex and dynamic problem scenarios [20].

In order to achieve the depicted goal, SD combines qualitative and quantitative modelling techniques. In qualitative modelling, the relevant factors, their dependencies - i.e. positive or negative influences and the magnitude of the effects - i.e. an abstract quantification expressed in percent of the total influence - can be illustrated. As a result, the key variables contributing to the realisation of the various objectives can be identified, performing a factor analysis. In addition to that in quantitative modelling concrete values can be plugged in the factors of the system model (such as number of students in European universities) and an explicit result of goal attainment can be calculated.

\subsubsection{Software-based illustration of the Bologna system model}

The complex Bologna system model was developed using the modelling software Consideo iMODELER [21] which supports a mapping of factors and their interdependencies. Associations are represented as positive or negative influences and characterised as small, medium or strong connections. Besides this qualitative description of dependencies the software also allows the quantification of the extent - e.g. measured in percentage points - by which one factor is influenced by another. Significant variables in the model could be identified by so-called "matrices of effects". In context of the Bologna Process this analysis allows to recognize important measures, which are relevant for the achievement of individual Bologna goals.

In the Bologna system model, qualitative and quantitative modelling have been realized. On the basis of the three dimensions economic efficacy, scientific efficacy and social cohesion all relevant factors of the Bologna Process were assigned to their superordinate variables according to their direct influence. In this way all Bologna goals and measures were hierarchically structured. Therefore the first levels illustrate the major objectives of the Bologna Process, which have the highest level of abstraction. As an excerpt from the total concept, the latter are shown in Fig.1. The full model can be accessed through the TeachING-LearnING.EU website's chapter "Innovative Hochschuldidaktik" and "Best Practice Europa". [19]

The end nodes of the system model finally represent tangible measures, which represent common implementable means for individual European universities in order to improve the status of the mapped Bologna goals. One simple example for such an end node is the implementation of the European Credit Transfer System (ECTS). The ECTS represents a solution in order to achieve the Bologna goal of Compatibility of European qualifications and degrees. By quantitatively evaluating the degree of realization of these measures and by knowing the relation between measures and objectives, one can ultimately calculate the degree of achievement of the dependent Bologna objectives. In order to allow such a calculation though, the quantification of the relations between any two model items was necessary. As an example:

- If a university has implemented the ECTS in the case of $80 \%$ of its offered degrees,

- and if the implementation of the ECTS is evaluated to be responsible for $50 \%$ of achieving the Compatibility of European qualifications and degrees,

- then this subordinate Bologna goal is met by this university by $40 \%$.

The quantification of the relations of the system model constitutes both an important and novel step for this research. It was therefore done through the effort of an expert consultation with a large panel size (see 2.1).

\section{VALIDATION OF THE MODEL AND ITS RESULTS}

\subsection{Participants}

To ensure objectivity and thereby to verify the content validity of the system model, an expert consultation was performed. Inaccurate illustrations of the Bologna goals and incorrect interpretations of their qualitative dependencies were ascertained and rectified in this manner. Since the study also aimed at quantifying the interrelations between the various Bologna goals, the participants were asked 
to estimate the strength of each dependency. For this reason qualitative and quantitative data were gathered in the study.

The participants were composed of 29 German experts in the field of higher education research. An additional criterion in the selection process was an intensive occupation with the Bologna Process in research or work on the side of the experts. Participants were recruited by telephone and email contacts. In this communication process the previous experiences with the topic were investigated. The participation in the study occurred on a purely voluntary basis. Also, the chosen form of online questionnaire was designed to not collect any personal data about the participants. Thus a detailed description of the sample is not possible. For further details on the panel, see chapter 3.2.

\subsection{Materials and Procedure}

To conduct the survey, an online-questionnaire has been designed using the software Unipark [23]. There, each question covers the influence of one model element on the other. Due to the considerable number of resulting questions and thus amount of time needed to complete the questionnaire, the survey has been divided into three parts. The participants have then been asked to respond to only one of these modules, while ensuring at the same time, that each module has been evaluated by at least ten experts. Each module dealt with one of the major dimensions of the Bologna Process system model. In total the questionnaire contained 47 items. It took around 30 minutes to complete one part of the questionnaire. After completing their chosen module, participants have been asked to continue the questionnaire on a voluntary basis in order to answer the other modules.

The questionnaire aimed at the verification of the collected variables and a quantification of the dependencies among the items of the presented system model. Consequently all variables and dependencies of the model have been investigated in the survey. At first, participants have been asked to estimate dependencies between the variables of the system model. As previously described, the structural mapping of the variables creates a hierarchy among them. As a result a distinction has been made between indicators on the one hand and higher target variables on the other hand. For example the factor employability is an indicator for the target variable economic efficacy. According to that, participants evaluated if and to what degree an indicator (e. g. employability) influences a target variable (e. g. economic efficacy). All ratings of dependencies between indicators and target variables have been made on a numeric five-point scale ranging from 0 to 100 percent. Furthermore participants have evaluated the so called "explained variance" of the target variable, measured in percentage points. The value expresses the experts' opinions, about the degree to which the behaviour of a given target variable (e.g. quality of life in Europe) is explained by the set of the variable's influencing factors (e.g. the set of economic efficacy, scientific efficacy and social cohesion).

Qualitative data has been gathered from statements and additional explanations in specific text boxes for commentary. There, participants have been primarily asked to assess the accuracy and the completeness of variables, indicators and their dependencies. In order to support the experts' understanding of the questionnaire, a software-based online illustration of the system model has been given with assistance of an online-application of the Consideo iMODELER [21].

\subsection{Analysis of the Data}

This chapter deals at first with the analysis methods of the qualitative and quantitative data gathered by the expert consultation. After that, the central results of the investigation are presented. Tab. 1 summarizes the most important results of the quantitative analysis of the expert consultation.

\subsubsection{Analysis of quantitative Data}

The Quantitative data comprises all ratings of dependencies between the variables of the Bologna system model and the estimation of the explained variance of these factors expressed by the participants of the expert consultation. A descriptive statistic of the quantitative data has been calculated using the software SPSS [24]. Data of one participant has been excluded from the data analysis because of invalid values. The sample sizes for individual items ranges from $n=9$ to $n=28$ depending on their distribution in the questionnaire.

On the basis of the average estimation of dependencies, a so-called absolute dependency between every variable has been calculated for the quantification of the system model. This parameter relativises the average numeric dependency between two variables taking into account the explained variance. 
Tab. 1: Extract of the results of quantitative data analysis of the expert consultation; The element $n$ represents the sample size, $r$ the range, $M$ the mean and $S D$ characterises the standard deviation of the expert ranking.

\begin{tabular}{|c|c|c|c|c|c|c|c|c|}
\hline No. & Variable & Indicator & $n$ & $r$ & $M$ & $S D$ & $\begin{array}{l}\text { explained } \\
\text { variance } \\
\text { (in \%) }\end{array}$ & $\begin{array}{l}\text { absolute } \\
\text { dependency } \\
\text { (in \%) }\end{array}$ \\
\hline \multirow[t]{3}{*}{1} & \multirow{3}{*}{$\begin{array}{l}\text { Quality of life in } \\
\text { Europe }\end{array}$} & Economic efficacy & \multirow[t]{3}{*}{28} & 50 & 74 & 16 & \multirow[t]{3}{*}{61} & 21 \\
\hline & & Scientific efficacy & & 75 & 64 & 21 & & 19 \\
\hline & & Social cohesion & & 75 & 74 & 16 & & 21 \\
\hline 2 & Economic efficacy & Employability & 17 & 50 & 76 & 16 & 70 & 70 \\
\hline \multirow[t]{3}{*}{3} & \multirow[t]{3}{*}{ Mobility } & Financial support (mobility) & \multirow[t]{3}{*}{16} & 50 & 80 & 21 & \multirow[t]{3}{*}{76} & 25 \\
\hline & & $\begin{array}{l}\text { Institutional support } \\
\text { (mobility) }\end{array}$ & & 50 & 84 & 15 & & 26 \\
\hline & & $\begin{array}{l}\text { Compatibility of European } \\
\text { qualifications and degrees }\end{array}$ & & 50 & 78 & 18 & & 24 \\
\hline \multirow[t]{3}{*}{4} & \multirow{3}{*}{$\begin{array}{l}\text { Compatibility of } \\
\text { European } \\
\text { qualifications and } \\
\text { degrees }\end{array}$} & Modularization of studies & \multirow[t]{3}{*}{16} & 75 & 64 & 22 & \multirow[t]{3}{*}{69} & 22 \\
\hline & & Implementation of ECTS & & 75 & 75 & 22 & & 26 \\
\hline & & $\begin{array}{l}\text { Study contents based on } \\
\text { international standards }\end{array}$ & & 75 & 62 & 22 & & 22 \\
\hline \multirow[t]{4}{*}{5} & \multirow[t]{4}{*}{ Social cohesion } & Intercultural understanding & \multirow[t]{4}{*}{14} & 50 & 68 & 18 & \multirow[t]{4}{*}{64} & 17 \\
\hline & & Lifelong learning & & 75 & 59 & 25 & & 14 \\
\hline & & Participative equity & & 50 & 77 & 18 & & 19 \\
\hline & & $\begin{array}{l}\text { Responsibility of } \\
\text { individuals }\end{array}$ & & 99 & 66 & 27 & & 16 \\
\hline \multirow[t]{6}{*}{6} & \multirow[t]{6}{*}{ Lifelong learning } & $\begin{array}{l}\text { Efficiency of academic } \\
\text { teaching }\end{array}$ & \multirow[t]{6}{*}{14} & 99 & 59 & 25 & \multirow[t]{6}{*}{76} & 10 \\
\hline & & $\begin{array}{l}\text { Willingness to lifelong } \\
\text { learning }\end{array}$ & & 50 & 89 & 16 & & 15 \\
\hline & & $\begin{array}{l}\text { Range of academic } \\
\text { programmes }\end{array}$ & & 75 & 75 & 24 & & 13 \\
\hline & & $\begin{array}{l}\text { Equal access to academic } \\
\text { programmes }\end{array}$ & & 50 & 75 & 20 & & 13 \\
\hline & & $\begin{array}{l}\text { Flexibility of academic } \\
\text { programmes }\end{array}$ & & 50 & 80 & 14 & & 13 \\
\hline & & $\begin{array}{l}\text { Counselling to educational } \\
\text { programmes }\end{array}$ & & 50 & 77 & 18 & & 13 \\
\hline \multirow[t]{4}{*}{7} & \multirow[t]{4}{*}{$\begin{array}{l}\text { Ability to participate in } \\
\text { higher education }\end{array}$} & $\begin{array}{l}\text { Flexibility of academic } \\
\text { programmes }\end{array}$ & \multirow[t]{4}{*}{14} & 75 & 73 & 23 & \multirow[t]{4}{*}{74} & 19 \\
\hline & & Learning support & & 75 & 70 & 22 & & 18 \\
\hline & & $\begin{array}{l}\text { Efficiency of academic } \\
\text { teaching }\end{array}$ & & 75 & 68 & 23 & & 18 \\
\hline & & $\begin{array}{l}\text { Financial support (social } \\
\text { gaps) }\end{array}$ & & 75 & 75 & 26 & & 20 \\
\hline
\end{tabular}

Based on the expert ratings and the resulting absolute dependencies an estimation of the importance of individual indicators for a target variable is possible. According to the percentage of absolute dependency, e. g. the indicator willingness to lifelong learning [12] shows a greater impact on the target variable lifelong learning [3] than efficiency of academic teaching [12] or flexibility of academic programmes [7]. In conclusion a consideration of the parameter absolute dependency enables an identification of the most important measures in the context of the Bologna Process.

\subsubsection{Analysis of qualitative Data}

The qualitative data from the expert consultation consists of statements, which have been contributed in the extra text fields in the online-questionnaire. All comments have been analysed against the benchmark of their significance within the Bologna declarations, memoranda and expert literature. 
The purpose of the present system model is to provide an objective mapping of all Bologna goals based on the official Bologna literature. Therefore a central problem of the qualitative analysis was to distinguish comments and supplements based on Bologna literature from additional evaluations, often rooted in subjective criticism of the Bologna Process. A few experts suggested further variables such as "health" or "cultural identity", which are not part of the goals of the Bologna Process, or missed the inclusion of criticism of the present higher education system in the system model. Such statements have been dismissed for addition to the system model.

In the expert comments the superordinate Bologna goal of quality of life in Europe, chosen to unify the various Bologna goals, has been questioned in several cases. Yet, no argument has been brought forward, which would have disrupted the logic of the argumentation, laid out in chapter 1.2.

In the course of the analysis of the qualitative data, the majority of the variables and dependencies of the system model have been re-evaluated and verified. This allowed for example to confirm the dependency of the factor adaptability of graduates [17] from the Bologna factors mobility [3], intercultural programmes [8], external internships within studies and reflective faculty. In addition, the definitions of the variables have been extended based on the statements. Moreover indicators have been added to respective target variables (e. g. new indicators for the factor quality of academic staff are attractiveness of the university [7], quality of personnel selection and personnel development) and additional connections between factors have been established. As a result, the verification of the model based on the qualitative data of the expert consultation delivered the pursued effect.

\section{DISCUSSION OF THE RESULTS}

\subsection{Summary}

The purpose of the present research was the development of a measuring instrument, which would enable universities to estimate their individual degree of Bologna target achievement, based on a complex system model of the Bologna goals. The system model was generated based on desk research of the official Bologna documents, including Bologna declarations, memoranda and expert literature. An expert consultation based on an online-questionnaire was performed in order to verify the system model and to quantify the dependencies between its variables.

As a result of the expert consultation, modifications of the initial Bologna system model have been applied. Illegitimate interdependencies were removed and new connections as well as new variables were added. In addition, the definitions of the variables were further detailed for reasons of clarification and precision. Consequently the intended verification of the system model has been achieved. On top of that, a quantification of the dependencies among the model's elements has been realized. The quantification of the absolute dependencies allowed the calculation of the individual importance of the various measures, available to a university.

\subsection{Limitations of the system model}

As previously described the presented system model is based on an intensive desk research. A first verification of the system model has been achieved by performing an expert consultation. Within this study a highly satisfactory number of $N=28$ complete data records has been considered in analysis. Moreover the knowledge of the involved experts in Bologna as well as their willingness for participation in this study have been proven through a combined telephone and email-communication. Nevertheless, difficulties of misinterpretation result from this validation method:

The experts participating in the survey have done so on a voluntary basis; nonetheless there is no certainty that all statements have been given conscientiously. There has been no control of conditions during the responding to the online-questionnaire. Moreover problems in understanding the method of the system model or the online-questionnaire have only been identified on the basis of the comments in the commentary text boxes. In addition to that, it is possible that relevant variables of the Bologna Process have been overlooked during the desk research or by the experts.

A major point of discussion in the expert consultation has been the global objective of the system model, i.e. Quality of life in Europe. Despite the subjective nature of these comments and their shortcoming to disrupt the argumentation put forward to make use of this specific item, it will continue to have to withstand further scrutiny. 
As another result of the expert consultation the model has been modified. New variables as well as dependencies have been implemented and unnecessary connections and factors of the model have been removed. Statements of the experts initiated these modifications. Given the fact that the system model is an attempt to illustrate all Bologna goals objectively, a few expert statements have been excluded from analysis according to their inadequacy (e.g. subjective criticisms of the Bologna Process or comments relating to the desire for ideal conditions of higher education). Since the criterion for the exclusion of additional factors and expert comments is their observed relevance within the available Bologna literature, the definition of exact system boundaries cannot be achieved terminally. Due to the interpretive character of an object of study like a political reform, it is not possible to reduce the blurredness of the system boundaries to an immaculate degree.

Overall, the conception and evaluation of the presented system model has raised various questions regarding the content, depiction and conclusions of the Bologna reform, as well as the feasibility of achieving the aim of mapping its goals in the first place. The investigation of these questions therefore has to be the subject of further research.

\subsection{Further research}

The purpose of this research was the development of a measuring instrument, which enables universities to estimate their individual Bologna goal achievement. The basis for this measuring instrument is the presented system model. For this reason further research will concentrate on the operationalisation of the end nodes of the model, i.e. measures available to the universities in order to achieve the Bologna Goals. On the basis of the operationalised system model a questionnaire will be designed. By means of the questionnaire the degree of achievement of the implementation of the Bologna Process in universities will be estimated within a pilot study at three German universities. By applying the collected data to the system model, the total degree of attainment of the Bologna goals will be calculated concerning these individual institutions.

\section{REFERENCES}

[1] TeachING-LearnING.EU (2011). Official website: http://www.teaching-learning.eu

[2] Jungmann et al. (2010). Shift from TeachING to LearnING. Anforderungen an die Ingenieurausbildung in Deutschland. In: Journal Hochschuldidaktik. Heft 02/ 2010.

[3] Bologna declaration (1999). Joint declaration of the European Ministers of Education of 19 June 1999.

[4] CRE (1999). The Bologna Declaration on the European space for higher education: an explanation. European Commission:

http://ec.europa.eu/education/policies/educ/bologna/bologna.pdf.

[5] Allegre et al. (1998). Sorbonne Joint Declaration - Joint declaration on harmonisation of the architecture of the European higher education system. http://www.bolognaberlin2003.de/pdf/Sorbonne_declaration.pdf.

[6] Prague communiqué (2001). Towards the European higher education area.

[7] Berlin communiqué (2003). Realising the European Higher Education Area.

[8] Bergen communiqué (2005). The European Higher Education Area - Achieving the goals.

[9] London communiqué (2007). Towards the European Higher Education Area: responding to challenges in a globalised world.

[10] Leuven communiqué (2009). The Bologna Process 2020 - The European Higher Education Area in the new decade.

[11] Budapest/Vienna communiqué (2010). Budapest-Vienna Declaration on the European Higher Education Area.

[12] Bucharest communiqué (2012). Making the Most of Our Potential: Consolidating the European Higher Education Area.

[13] Kehm (2010). The Future of the Bologna Process - The Bologna Process of the Future. European Journal of Education 45, Nr. 4 (2010): 529-534. 
[14] Keeling (2006). The Bologna Process and the Lisbon Research Agenda: the European Commission's expanding role in higher education discourse". European Journal of Education 41, Nr. 2 (2006): 203-223.

[15] Ceylan et al. (2011). Kompetenz in der Hochschuldidaktik: Ergebnisse einer Delphi-Studie über die Zukunft der Hochschullehre. Springer: Wiesbaden.

[16] Witte et al. (2011). Wirkungen von Bologna auf Studierende: Eine Bestandsaufnahme in 48 Hochschulsystemen. In S. Nickel, hrsg. Der Bologna-Prozess aus Sicht der Hochschulforschung. Analysen und Impulse für die Praxis. CHE Arbeitspapierte. Gütersloh: Centrum für Hochschulentwicklung gGmbH.

[17] Commission of the European Communities (2001). Communication from the Commission Making a European Area of Lifelong Learning a Reality.

[18] Linley et. al. (2009). Measuring happiness: The higher order factor structure of subjective and psychological well-being measures. Personality and Individual Differences, 47(8), S.878-884.

[19] OECD (2011). How's Life?: Measuring well-being, OECD Publishing. http://dx.doi.org/10.1787/9789264121164-en.

[20] Sterman, J.D. (2000). Business Dynamics: Systems Thinking and Modelling for a Complex World. McGraw-Hill: Irvine.

[21] Consideo $\mathrm{GmbH}$ (2012). iMODELER 3.0.

[22] TeachING-LearnING.EU (2011). Official website: http://www.teachinglearning.eu/innovative_hochschuldidaktik/best_practice_europa.html

[23] Unipark. QuestBack - EFS Survey.

[24] IBM Software (2012). SPSS 20. 